\title{
Identificação do potencial ornamental e avaliação de desempenho de genótipos de pimenteiras
}

\section{Gabriela Corrêa Morais ${ }^{1}, *$, Laís dos Santos Neri da Silva ${ }^{2}$, Leandra Oliveira Magalhães ${ }^{3}$, Lucas de Oliveira Lima ${ }^{3}$, Mayara Rodrigues e Silva ${ }^{4}$ e Raimundo Nonato Oliveira Silva ${ }^{5}$}

1Universidade Federal de Goiás. Escola de Agronomia. Programa de Pós-Graduação em Genética e Melhoramento de Plantas. Av. Esperança, s/n. Campus Samambaia. Goiânia-GO, Brasil (CEP 74690-900).*E-mail: gabrielacorreamorais@gmail.com.

2Universidade Federal do Piauí. Centro de Ciências Agrárias. Programa de Pós-Graduação em Genética e Melhoramento. Bairro Ininga, s/n. Campus Ministro Petrônio Portela. Teresina-PI, Brasil (CEP 64049-550).

3Universidade Estadual de Santa Cruz. Programa de Pós-Graduação em Genética e Biologia Molecular. Rodovia Jorge Amado, km 16. Bairro Salobrinho. Campus Soane Nazaré de Andrade. Ilhéus-BA, Brasil (CEP 45662-900).

${ }^{4}$ Universidade Estadual do Norte Fluminense Darcy Ribeiro. Centro de Ciências e Tecnologias Agropecuárias. Programa de Pós-Graduação em Genética e Melhoramento de Plantas. Av. Alberto Lamego, 2000. Parque Califórnia. Campos dos Goytacazes-RJ, Brasil (CEP 28013-602).

5Universidade Federal do Piauí. Curso de Graduação em Licenciatura em Ciências Biológicas. Campus Amílcar Ferreira Sobral. BR 343, km 3,5. Bairro Meladão. Floriano-PI, Brasil (CEP 64808-605).

Resumo. Objetivou-se identificar genótipos de pimenteiras com potencial ornamental e avaliar seus desempenhos em diferentes tipos de substratos e volumes de vaso. A caracterização morfológica foi realizada utilizando 10 genótipos de pimenteiras com base em seis descritores qualitativos e nove descritores quantitativos, para fins de seleção. Uma vez identificados os mais promissores para ornamentação, estes foram avaliados utilizando delineamento inteiramente casualizado, em arranjo fatorial $3 \times 3$ x 4 (três genótipos, três tipos de substratos, quatro volumes de vaso), com duas repetições. Para avaliação de desempenho, foram utilizados quatro caracteres quantitativos. Os resultados obtidos no presente estudo evidenciam os genótipos GEN38, GEN40 e GEN75 como os mais promissores a serem utilizados para fins ornamentais. Na avaliação de desempenho de pimentas com potencial ornamental, foi possível verificar diferenças significativas entre os fatores estudados isoladamente e suas interações. Recomenda-se o cultivo dos genótipos GEN38 e GEN75 em vaso V2 (680 mL). Já o GEN40 pode ser produzido utilizando-se o recipiente V4 $(2.600 \mathrm{~mL})$. Dentre os substratos

Recebido 05/05/2020

Aceito $29 / 08 / 2020$

Publicado $31 / 08 / 2020$

Acesso aberto

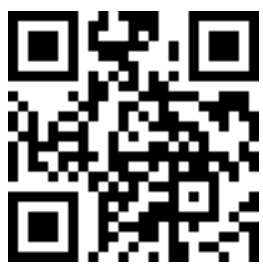

ISSN 2359-1412/RBGAS-2020-00073/2020/7/16/37/1041

Rev. Bras. Gest. Amb. Sustent.

http://revista.ecogestaobrasil.net 
utilizados, recomenda-se o de menor custo, composto por esterco caprino, esterco bovino, palha de arroz e areia.

Palavras-chave: Capsicum spp.; Substratos; Volumes de vaso; Análise de regressão.

\begin{abstract}
Identification of ornamental potential and performance evaluation of pepper genotypes. This study aims to identify genotypes of pepper with ornamental potential and evaluate their performances on different types of substrates and vase volumes. For morphological characterization, 10 pepper genotypes were used based on a list containing six qualitative descriptors and nine quantitative descriptors for selection purposes. Once identified the most promising for ornamentation, these were sown and arranged in a $3 \times 3 \times 4$ factorial scheme (three genotypes, three substrate types, four vase volumes), with two repetitions. These were characterized based on a list of four quantitative descriptors. The results obtained in this study indicate the genotypes GEN38, GEN40 and GEN75 as the most promising to be used for ornamental purposes. In the performance evaluation of peppers with ornamental potential, it was possible to verify significant differences between the studied factors and their interactions. Cultivation of genotypes GEN38 and GEN75 in V2 $(680 \mathrm{~mL})$ pot is recommended. GEN40 can be produced using V4 $(2,600 \mathrm{~mL})$ vase. Among the substrates used, we recommend the lowest cost, consisting of goat manure, cattle manure, rice straw and sand.
\end{abstract}

Keywords: Capsicum spp.; Substrates; Vase volumes; Regression analysis.

\author{
D) 0000-0002-9532-9057 \\ Gabriela Corrêa \\ Morais \\ D) 0000-0001-9131-1936 \\ Laís dos Santos Neri \\ da Silva \\ D) 0000-0003-4901-6241 \\ Leandra Oliveira \\ Magalhães \\ (D) 0000-0002-4329-8295 \\ Lucas de Oliveira Lima \\ (D) 0000-0002-4281-397X \\ Mayara Rodrigues e \\ Silva \\ D) 0000-0002-9987-0043 \\ Raimundo Nonato \\ Oliveira Silva
}

\section{Introdução}

0 vasto aproveitamento comercial das pimenteiras engloba desde a comercialização de frutos in natura e/ou processados sob a forma de pápricas, molhos, conservas ou geleias, até a fabricação de sprays, medicamentos e cosméticos (Pinto et al., 2013). Segundo Silva et al. (2015), é também crescente a comercialização de pimentas para a ornamentação de interiores. O agronegócio de flores e plantas ornamentais revelase promissor no Brasil (Neves e Pinto, 2015), sendo responsável por empregar direta e indiretamente mais de 120 mil trabalhadores em todo o país (Junqueira e Peetz, 2014).

A folhagem variegada, o porte anão, os frutos com diferentes tamanhos e colorações variadas durante os diferentes estádios de maturação, além da durabilidade de suas folhas e frutos, constituem algumas das características que agregam valor ornamental às pimenteiras (Carvalho et al., 2006). A maioria delas produz ainda frutos pungentes, os quais também podem ser utilizados na culinária como condimento, diferentemente de muitas outras espécies de plantas ornamentais que são inadequadas à alimentação (Neitzke et al., 2016). A capacidade de crescerem em vasos como plantas perenes e com uma quantidade limitada de substrato também constituem atributos importantes que tornam as pimentas uma ótima opção para fins de ornamentação (Pinto et al., 2010).

No que tange ao cultivo de pimenteiras ornamentais, o tipo de substrato apresenta-se como um dos fatores capazes de interferir no sucesso da formação e 
desenvolvimento de mudas. Além disso, a produção de plantas envasadas é dependente do tamanho dos recipientes utilizados, o qual afeta diretamente o crescimento do sistema radicular das espécies vegetais (Furtini Neto et al., 2015).

Tendo em vista o conjunto de características de alto valor estético atribuído às pimenteiras Capsicum spp. e a escassez de cultivares de pimentas destinadas à ornamentação (Rêgo et al., 2012), torna-se relevante o desenvolvimento de trabalhos relacionados à identificação de genótipos que podem ser explorados com a finalidade ornamental em futuros programas de melhoramento (Neitzke et al., 2016). Além disso, é necessária a realização de estudos que avaliem a performance das pimenteiras quando cultivadas em diferentes tipos de substratos e diferentes volumes de vasos, permitindo assim o estabelecimento das condições de cultivo mais eficientes e que garantam menores custos de produção.

Diante do exposto, o presente trabalho teve como objetivo identificar genótipos de pimenteiras com potencial ornamental e avaliar seus desempenhos em diferentes tipos de substratos e volumes de vaso.

\section{Material e métodos}

\section{Montagem dos experimentos}

Foram conduzidos dois experimentos em casa de vegetação da Universidade Federal do Piauí, Campus Amílcar Ferreira Sobral (UFPI/CAFS), Floriano (coordenadas de referência $6^{\circ} 47^{\prime} 28.9^{\prime \prime} \mathrm{S}, 43^{\circ} 2^{\prime} 50.3^{\prime \prime} \mathrm{W}$ ). O primeiro experimento foi realizado entre outubro de 2018 e maio de 2019. Já o segundo experimento foi desenvolvido entre os meses de julho e novembro de 2019.

Para a identificação de genótipos com potencial ornamental (experimento 1), foram utilizados 10 genótipos de pimenteiras pertencentes à coleção de sementes do Laboratório de Ecologia, Recursos Genéticos e Evolução, UFPI/CAFS (Tabela 1).

Tabela 1. Identificação e procedência dos 10 genótipos avaliados quanto ao seu potencial ornamental advindos da coleção de sementes do Laboratório de Ecologia, Recursos Genéticos e Evolução, UFPI/CAFS. Floriano-PI, Brasil, 2019.

\begin{tabular}{|l|l|c|}
\hline Genótipo & Procedência & Espécie \\
\hline GEN11 & Teresina, Piauí, Brasil & Capsicum baccatum L. \\
\hline GEN26 & Floriano, Piauí, Brasil & Capsicum frutescens L. \\
\hline GEN32 & Floriano, Piauí, Brasil & Capsicum chinense Jacq. \\
\hline GEN38 & Floriano, Piauí, Brasil & Capsicum annuum L. \\
\hline GEN40 & Floriano, Piauí, Brasil & Capsicum annuum L. \\
\hline GEN63 & Floriano, Piauí, Brasil & Capsicum chinense Jacq. \\
\hline GEN75 & Floriano, Piauí, Brasil & Capsicum annuum L. \\
\hline GEN77 & Floriano, Piauí, Brasil & Capsicum annuum L. \\
\hline GEN89 & Teresina, Piauí, Brasil & Capsicum baccatum L. \\
\hline GENZ3 & Floriano, Piauí, Brasil & Capsicum annuum L. \\
\hline
\end{tabular}

$\mathrm{Na}$ semeadura do experimento 1, foram utilizados recipientes plásticos com capacidade de $180 \mathrm{~mL}$ preenchidos com substrato comercial Garden Plus ${ }^{\circledR} .0$ transplantio foi realizado em vasos de $1730 \mathrm{~mL}$ (V3) 50 dias após a semeadura, quando as mudas apresentaram entre quatro e seis pares de folhas definitivas. 0 delineamento experimental adotado foi o inteiramente casualizado, com três repetições e uma planta por parcela. Realizou-se rega manual das plantas com o auxílio de mangueira, duas vezes ao dia, até a 
saturação total do substrato, recebendo todas elas o mesmo quantitativo de água. Os tratos culturais foram executados conforme recomendações para a cultura (Filgueira, 2008).

Para a avaliação do desempenho de pimenteiras (experimento 2), os genótipos selecionados com base em seus atributos ornamentais foram semeados em recipientes plásticos com capacidade de $180 \mathrm{~mL}$ contendo substrato comercial Garden Plus ${ }^{\circledR}$. 0 transplantio foi realizado 50 dias após a semeadura, sendo utilizada uma planta por vaso. Adotou-se o mesmo procedimento de rega do experimento 1 e o delineamento experimental inteiramente casualizado, com duas repetições, em esquema fatorial de $3 \times 3 \times 4$, com três genótipos, três tipos de substratos (S1, S2 e S3) e quatro volumes de vasos (V1, V2, V3 e V4), totalizando 36 tratamentos.

$\mathrm{O}$ substrato $\mathrm{S} 1$ foi formado por uma mistura de esterco caprino: esterco bovino: composto orgânico comercial Pole Fértil ${ }^{\circledR}$ : palha de arroz: areia, na proporção de $1: 1: 1: 0,5: 2$. 0 substrato S2 foi constituído por esterco caprino: esterco bovino: composto orgânico doméstico: palha de arroz: areia, na proporção de 1: 1: 1: 0,5: 2. Já o substrato S3 foi preparado com esterco caprino : esterco bovino : palha de arroz : areia, na proporção de $1: 1: 0,5: 2$.

Os vasos utilizados no experimento 2 apresentaram as seguintes dimensões: V1, com diâmetro inferior de $7,5 \mathrm{~cm}$, diâmetro superior de $11 \mathrm{~cm}$, altura de $7 \mathrm{~cm}$ e capacidade volumétrica de $300 \mathrm{~mL}$; V2, com diâmetro inferior de 9,5 cm, diâmetro superior de $14 \mathrm{~cm}$, altura de 11,5 cm e capacidade volumétrica de $680 \mathrm{~mL}$; V3, com diâmetro inferior de 12,5 $\mathrm{cm}$, diâmetro superior de 17,5 cm, altura de $15 \mathrm{~cm}$ e capacidade volumétrica de $1.730 \mathrm{~mL}$; V4, com diâmetro inferior de $12 \mathrm{~cm}$, diâmetro superior de $14 \mathrm{~cm}$, altura de $20 \mathrm{~cm}$ e capacidade volumétrica de $2.600 \mathrm{~mL}$.

\section{Caracteres avaliados}

A identificação de genótipos com potencial ornamental (experimento 1) teve como base uma lista contendo seis características qualitativas e nove características quantitativas. Os descritores qualitativos utilizados foram: densidade das folhas, cor da folha, posição da flor, cor da corola, cor do fruto no estádio intermediário e cor do fruto no estádio maduro.

Para os dados quantitativos, utilizou-se a média da parcela para cada característica. Foram empregados os seguintes caracteres quantitativos: comprimento da folha, largura da folha, comprimento do fruto, largura do fruto, comprimento do pedicelo, altura da planta, diâmetro da copa, número de dias para floração e número de dias para frutificação. As mensurações de altura e diâmetro da copa foram realizadas com o auxílio de uma régua graduada em $\mathrm{cm}$. Já as mensurações de folhas e frutos foram realizadas com o auxílio de paquímetro digital Pantec ${ }^{\circledR}$ graduado em $\mathrm{mm}$, medindo-se cinco folhas e cinco frutos de cada planta.

A avaliação do desempenho dos genótipos com potencial ornamental (experimento 2) baseou-se em quatro descritores quantitativos: altura da planta, diâmetro da copa, comprimento da folha e largura da folha.

\section{Análises estatísticas}

Os valores médios dos caracteres quantitativos referentes ao experimento 1 foram submetidos à análise de componentes principais, obtendo-se em seguida um gráfico de dispersão biplot.

No experimento 2, os dados foram submetidos à análise de variância e, conforme a significância, os fatores qualitativos foram sujeitos à comparação de médias pelo teste Tukey, a $5 \%$ de probabilidade. Para os fatores quantitativos, utilizou-se análise de regressão. 
Todas as análises estatísticas foram realizadas com o auxílio do programa $R$ (R Core Team, 2019).

\section{Resultados}

A caracterização morfológica dos 10 genótipos de pimenteiras utilizando descritores qualitativos resultou em um número mínimo de duas e um máximo de cinco classes fenotípicas distintas (Tabela 2).

Tabela 2. Classes fenotípicas observadas na caracterização morfológica de 10 genótipos de pimenteiras utilizando-se descritores qualitativos. Floriano-PI, Brasil, 2019.

\begin{tabular}{|c|c|c|c|c|c|c|}
\hline \multirow{2}{*}{ Genótipo } & \multicolumn{6}{|c|}{ Característica } \\
\hline & DF & CF & PFLO & $\mathrm{CCO}$ & CFRUTI & CFRUTM \\
\hline GEN11 & Escassa & $\begin{array}{l}\text { Verde } \\
\text { claro }\end{array}$ & Intermediária & Branca & Verde & Vermelho \\
\hline GEN26 & Escassa & $\begin{array}{c}\text { Verde } \\
\text { claro }\end{array}$ & Ereta & Branca & Verde & Vermelho \\
\hline GEN32 & Intermediária & Verde & Intermediária & Branca & Alaranjado & Laranja \\
\hline GEN38 & Densa & $\begin{array}{c}\text { Verde } \\
\text { escuro }\end{array}$ & Intermediária & Branca & Amarelo & $\begin{array}{c}\text { Amarelo- } \\
\text { limão }\end{array}$ \\
\hline GEN40 & Densa & $\begin{array}{l}\text { Verde } \\
\text { escuro }\end{array}$ & Intermediária & $\begin{array}{c}\text { Branca } \\
\text { com } \\
\text { margens } \\
\text { púrpuras }\end{array}$ & Roxo & Vermelho \\
\hline GEN63 & Escassa & Verde & Ereta & Branca & Alaranjado & Laranja \\
\hline GEN75 & Densa & $\begin{array}{l}\text { Verde } \\
\text { escuro }\end{array}$ & Intermediária & Roxa & Roxo escuro & Vermelho \\
\hline GEN77 & Intermediária & Verde & Intermediária & Branca & Alaranjado & Vermelho \\
\hline GEN89 & Intermediária & $\begin{array}{l}\text { Verde } \\
\text { claro }\end{array}$ & Ereta & Branca & Verde & Vermelho \\
\hline GENZ3 & Intermediária & $\begin{array}{l}\text { Verde } \\
\text { escuro }\end{array}$ & Intermediária & Branca & Verde & Vermelho \\
\hline
\end{tabular}

"DF" = Densidade das folhas; "CF" = Cor da folha; "PFLO" = Posição da flor; "CCO" = Cor da corola; "CFRUI" = Cor do fruto no estádio intermediário; "CFRUTM" = Cor do fruto no estádio maduro.

Os genótipos GEN38, GEN40 e GEN75 apresentaram uma folhagem densa. Segundo Silva et al. (2017), esta constitui uma característica desejável para fins de ornamentação. GEN32, GEN63 e GEN77 apresentam folhas verdes, enquanto GEN38, GEN40, GEN75 e GENZ3 manifestaram uma folhagem verde-escura. Conforme Nietzke et al. (2016), em se tratando de pimentas ornamentais, interessam folhas com coloração, preferencialmente verde-escura, capazes de contrastarem com os frutos, atribuindo-lhes um maior realce.

Estruturas florais com margens púrpura e coloração roxa foram observadas, respectivamente, em GEN40 e GEN75, enquanto os genótipos GEN26, GEN63 e GEN89 caracterizaram-se pela presença de flores eretas. Apesar das pimentas possuírem flores diminutas, estas são capazes de agregarem um valor estético considerável, sendo preferíveis flores com um colorido intenso e erguidas verticalmente, facilitando assim sua visualização em meio à folhagem (Melo et al., 2014).

Os frutos dos genótipos GEN32, GEN38, GEN40, GEN63, GEN75 e GEN77 apresentaram colorações variadas durante seu desenvolvimento, possuindo cores 
diferentes de verde quando em estádio intermediário. Segundo Carvalho et al. (2006), este constitui um forte atributo ornamental das pimenteiras. Quando maduros, os frutos de GEN11, GEN26, GEN40, GEN75, GEN77, GEN89 e GENZ3 manifestaram uma coloração vermelha, enquanto os do genótipo GEN38 exibiram uma coloração amarelo-limão. Nietzke et al. (2016) afirmam que pimentas com frutos vermelhos ou amarelos vibrantes são capazes de exercerem uma maior atração por parte dos consumidores.

Os genótipos GEN40 e GEN75 apresentaram folhagem densa e verde-escura, flores coloridas e frutos que variaram do roxo ao vermelho. Além de atributos como uma maior densidade foliar, folhas verde-escuras e frutos com coloração intermediária diferente da cor verde, a presença de frutos amarelos-vibrantes quando maduros constitui um forte elemento estético capaz de qualificar o GEN38 para uso ornamental.

Com base nos caracteres qualitativos, evidenciamos os genótipos GEN38, GEN40 e GEN75 como os esteticamente mais promissores a serem utilizados para fins ornamentais.

As posições relativas dos genótipos e dos caracteres quantitativos, considerando os dois primeiros componentes (88,30\% da variação), mostram que os genótipos GEN38, GEN40, GEN75 e GEN77 ficaram reunidos em um mesmo grupo por possuírem os menores valores para todas as características quantitativas analisadas (Figura 1).

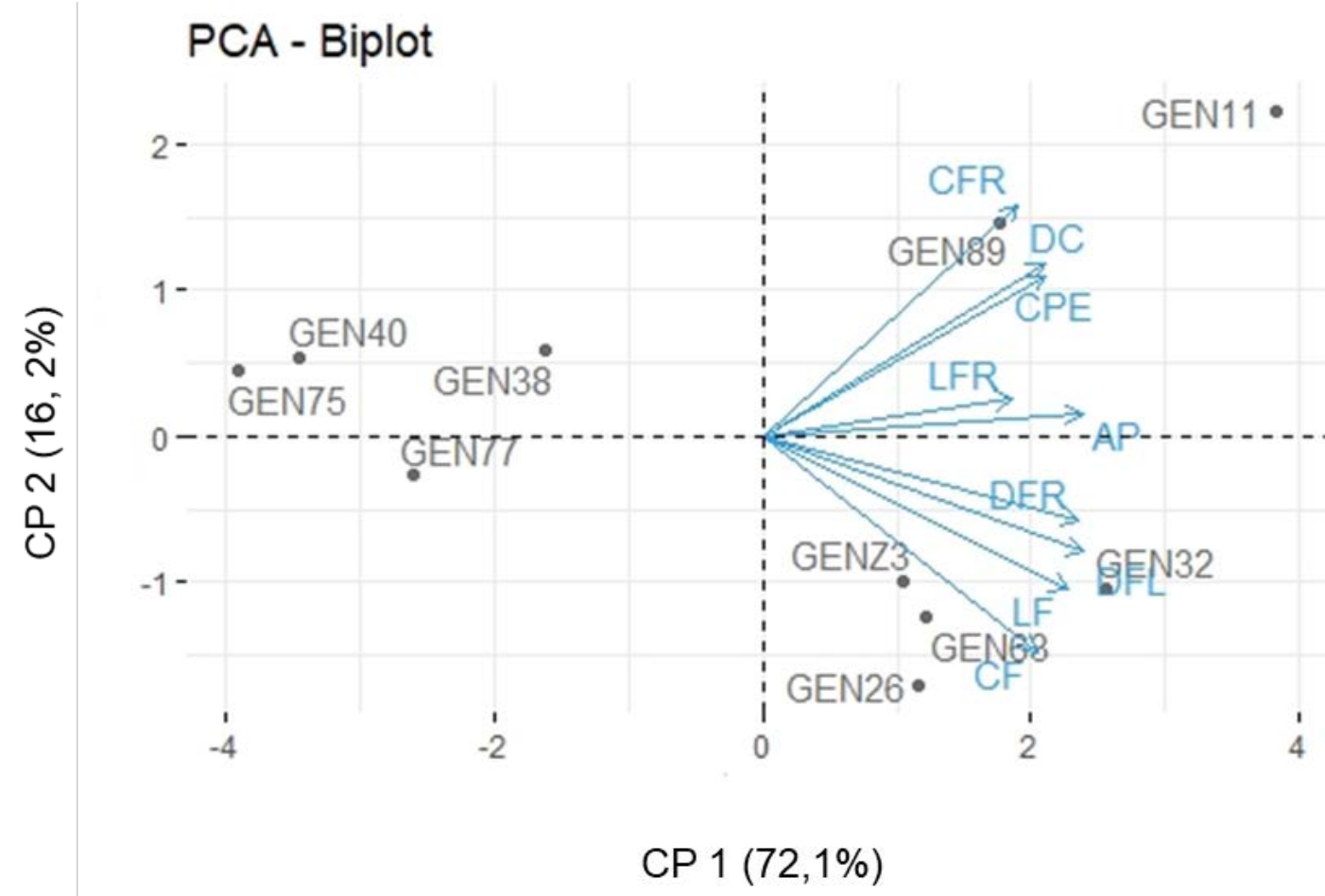

Figura 1. Dispersão gráfica de 10 genótipos de Capsicum spp. obtida pela Análise de Componentes Principais a partir de nove descritores quantitativos: altura da planta (AP), diâmetro da copa (DC), comprimento da folha (CF), largura da folha (LF), comprimento do fruto (CFR), largura do fruto (LFR), comprimento do pedicelo (CPE), dias para floração (DFLO) e dias para frutificação (DFRUT). Floriano-PI, Brasil, 2019.

Genótipos de pimenteiras com menores alturas são os mais indicados para cultivo em vasos como plantas ornamentais (Santos Pessoa et al., 2018), enquanto os de maior porte podem ser cultivados em jardins e empregados no paisagismo (Nietzke et al., 2010). 
Já um menor diâmetro da copa e folhas reduzidas constituem elementos importantes na determinação da qualidade de uma pimenta ornamental, uma vez que estes exercem um papel decisivo na harmonia entre a arquitetura da planta e o tamanho do vaso (Barroso et al., 2012).

Os menores valores médios para comprimento e largura dos frutos foram observados para os genótipos GEN38, GEN40, GEN75 e GEN77 (Figura 1). De acordo com Büttow et al. (2010), quanto menores as dimensões dos frutos de uma pimenteira, maior será a quantidade de frutos por ela produzidos. Além disso, frutos pequenos são essencialmente mais eretos, o que os tornam mais proeminentes em relação à folhagem e mais visíveis aos consumidores (Silva et al., 2015).

GEN38, GEN40, GEN75 e GEN77 distinguiram-se por possuírem os menores valores médios para número de dias para floração e frutificação (Figura 1). Estes atributos conferem aos referidos genótipos valor ornamental, uma vez que aos produtores interessam, sobretudo, plantas que apresentam floração e frutificação precoces, o que garante uma rápida comercialização das pimenteiras (Silva et al., 2017).

Segundo Carpentieri-Pípolo et al. (2000), a identificação de genótipos promissores para uso ornamental com base apenas em estudos de distância genética, sem considerar os seus próprios atributos, pode não ser uma boa estratégia para os programas de melhoramento, devendo-se recomendar acessos que também possuam caracteres estéticos altamente desejáveis (Nietzke et al., 2010). Logo, considerando o ideótipo de pimenta proposto, que consiste em plantas de pequeno porte, com folhagem densa, folhas diminutas e com coloração verde-escura, frutos pequenos e com cores variadas e flores eretas e coloridas, além de floração e frutificação precoces, são recomendados para fins de ornamentação o GEN38, GEN40 e GEN75, uma vez que estes reuniram o maior número de atributos ornamentais dentre os genótipos estudados.

$\mathrm{Na}$ avaliação de desempenho de pimentas com potencial ornamental (GEN38, GEN40 e GEN75), foi possível identificar diferenças significativas entre os fatores estudados isoladamente (genótipos, tipos de substratos e volumes de vasos) e suas interações para a maioria das características analisadas (Tabela 3).

Tabela 3. Resumo da análise de variância das características altura da planta, diâmetro da copa, comprimento da folha e largura da folha. Floriano-PI, Brasil, 2019.

\begin{tabular}{|c|c|c|c|c|c|}
\hline \multirow{2}{*}{ FV } & \multirow{2}{*}{ GL } & \multicolumn{4}{|c|}{ QM } \\
\cline { 3 - 6 } & & AP & DC & CF & LF \\
\hline G & 2 & $37303,1^{* *}$ & 1051,5 & $1651,3^{* *}$ & $139,1^{* *}$ \\
\hline S & 2 & 1063,0 & 1186,1 & 33,6 & 7,9 \\
\hline V & 3 & $9035,4^{* *}$ & $14285,5^{* *}$ & $71,9^{*}$ & $47,1^{* *}$ \\
\hline G x S & 4 & 966,9 & 1478,5 & 12,7 & 2,4 \\
\hline G x V & 6 & $2574,3^{* *}$ & 1602,5 & 41,2 & $6,6^{* *}$ \\
\hline S x V & 6 & 936,1 & 2676,3 & 37,3 & 3,5 \\
\hline Gx S V V & 12 & 518,7 & 2260,0 & 39,5 & 3,0 \\
\hline
\end{tabular}

$\mathrm{FV}=$ Fonte de variação; $\mathrm{G}=$ Genótipo; $\mathrm{S}=$ Substrato; $\mathrm{V}=$ Volume; $\mathrm{GL}=\mathrm{Grau}$ de liberdade; $\mathrm{QM}=$ Quadrados médios; $\mathrm{AP}=$ Altura da planta; $\mathrm{DC}=$ Diâmetro da copa; $\mathrm{CF}=$ Comprimento da folha; $\mathrm{LF}=$ Largura da folha. ${ }^{*}=$ Significativo a $5 \%$ de probabilidade pelo teste F; ${ }^{*}$ = Significativo a $1 \%$ de probabilidade pelo teste $\mathrm{F}$.

A interação genótipo x volume foi capaz de alterar significativamente a altura das plantas ornamentais (Tabela 4). Segundo Lima et al. (2013), a altura ideal de uma pimenta 
ornamental constitui um atributo de difícil determinação, pois varia de acordo com a preferência do consumidor. Nota-se, porém, uma maior predisposição por parte do mercado por plantas que apresentam um porte anão.

De acordo com os padrões de comercialização de pimentas ornamentais, estas devem apresentar uma altura entre 12 e $33 \mathrm{~cm}$ (Veiling Holambra, 2019). Portanto, o vaso V1 (300 mL) apresenta-se como impróprio para o cultivo dos genótipos estudados, visto que a altura média atingida pelos mesmos neste recipiente foi inferior a $12 \mathrm{~cm}$. 0 GEN40 deverá ser cultivado em volume de vaso V4 $(2.600 \mathrm{~mL})$. Já para o GEN38 e GEN75, recomenda-se o vaso V2 $(680 \mathrm{~mL})$, visto que este é capaz de assegurar o crescimento adequado destas pimenteiras, além de garantir os menores custos de produção.

Tabela 4. Valores médios para altura $(\mathrm{em} \mathrm{cm})$ de genótipos de pimenteiras com potencial ornamental cultivadas em recipientes de diferentes volumes. Floriano-PI, Brasil, 2019.

\begin{tabular}{|c|c|c|c|c|}
\hline \multirow{2}{*}{ Genótipo } & \multicolumn{3}{|c|}{ Volume } \\
\cline { 2 - 5 } & $\mathbf{3 0 0} \mathbf{~ m L}$ & $\mathbf{6 8 0} \mathbf{~} \mathbf{L}$ & $\mathbf{1 . 7 3 0} \mathbf{~ m L}$ & $\mathbf{2 . 6 0 0} \mathbf{~ m L}$ \\
\hline GEN38 & $8,5 \mathrm{ab}$ & $13,0 \mathrm{~b}$ & $13,0 \mathrm{~b}$ & $8,9 \mathrm{~b}$ \\
\hline GEN40 & $8,4 \mathrm{~b}$ & $8,8 \mathrm{c}$ & $11,0 \mathrm{~b}$ & $12,1 \mathrm{~b}$ \\
\hline GEN75 & $11,8 \mathrm{a}$ & $18,6 \mathrm{a}$ & $20,4 \mathrm{a}$ & $18,3 \mathrm{a}$ \\
\hline
\end{tabular}

Médias seguidas de mesma letra na coluna não diferem estatisticamente entre si pelo teste de Tukey a $5 \%$ de probabilidade.

Os diferentes volumes de vaso afetaram a altura dos genótipos estudados, observando-se, por exemplo, um comportamento linear para o GEN40 (Figura 2B), indicando que, quanto maior o volume do recipiente utilizado, maior será a altura. Em estudo desenvolvido por Almeida et al. (2015) envolvendo soja cultivada em vasos, também foi possível observar uma tendência ao aumento da estatura das plantas com o aumento do volume dos recipientes. Isto pode ser explicado pela maior disponibilidade de substrato para suprir as exigências de crescimento e desenvolvimento dos vegetais (Pinto et al., 2010).

Para os genótipos GEN38 e GEN75, o modelo de regressão que melhor se ajustou foi o quadrático (Figura 2A e 2C). Em ambos, as maiores médias para altura de planta foram atingidas quando estas foram mantidas em vasos V3 (1730 mL). Logo, a fim de garantir a produção de pimentas ornamentais com um menor porte e reduzir seus custos de produção, sugere-se que os genótipos GEN38 e GEN75 sejam cultivados em vasos V2.

No presente estudo, os diferentes tipos de substratos não interferiram na altura das plantas nem nas demais características estudadas, possivelmente devido ao fato de possuírem uma composição semelhante. Araújo Neto et al. (2009), ao avaliarem o crescimento de mudas de pimentão em oito diferentes tipos de substratos resultantes da mistura de resíduos agrícolas, tais como esterco bovino, casca de coco triturada e casca de arroz carbonizada, constataram que estes foram capazes de afetarem uma série de atributos, como por exemplo a altura destas hortaliças. 


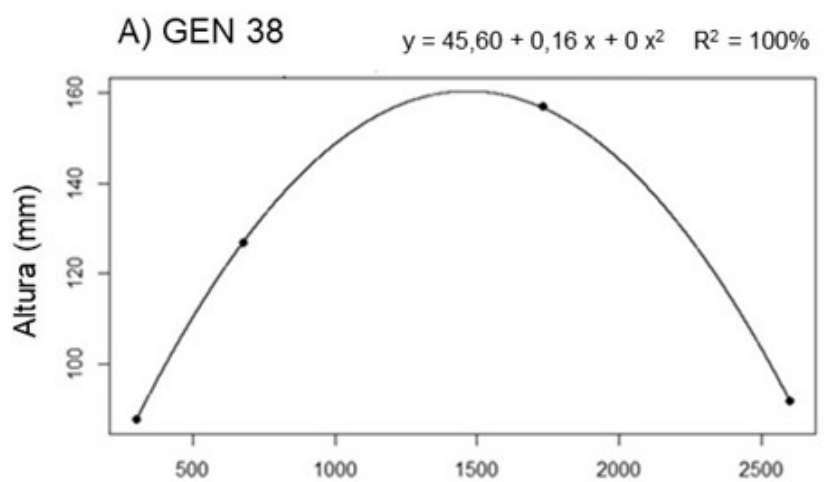

B) GEN 40

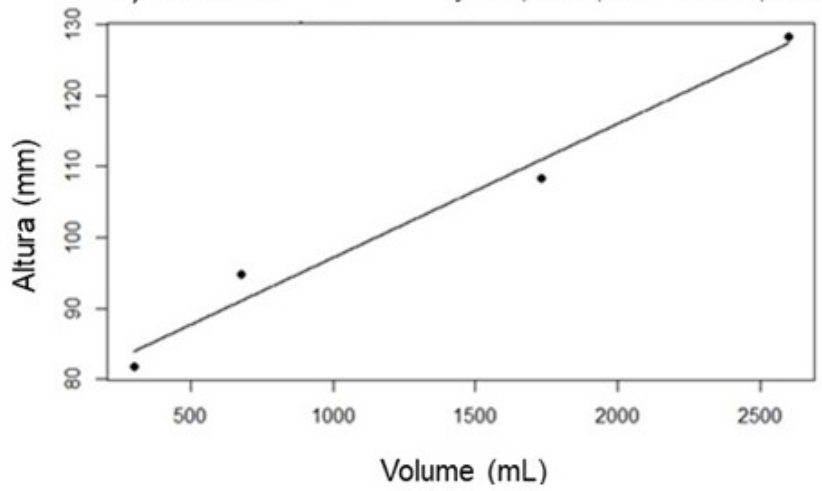

C) GEN 75

$y=107,19+0,14 x+0 x^{2} \quad R^{2}=80,91 \%$

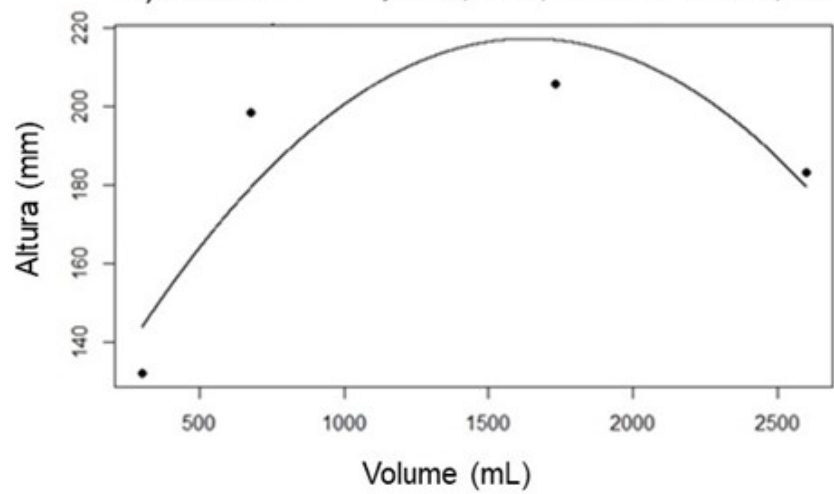

Figura 2. Altura da planta de três genótipos de pimenteiras ornamentais cultivadas em recipientes de diferentes volumes. Floriano-PI, Brasil, 2019.

Os volumes de vaso foram capazes de interferirem no diâmetro da copa, sendo o vaso V3 o que proporcionou os maiores valores médios para a característica. Pinto et al. (2010), ao avaliarem o desempenho de duas variedades e cinco acessos de pimenteiras ornamentais em quatro diferentes volumes de vasos, observaram um comportamento linear crescente entre os tamanhos dos recipientes utilizados e o diâmetro da maioria das plantas. Entretanto, em nosso estudo, o modelo quadrático foi o que mais se ajustou para explicar o desempenho dos genótipos para a referida característica (Figura 3). Estes resultados sugerem que, embora o vaso V4 possua um maior volume, este não proporciona um bom desenvolvimento do sistema radicular devido às suas dimensões. 


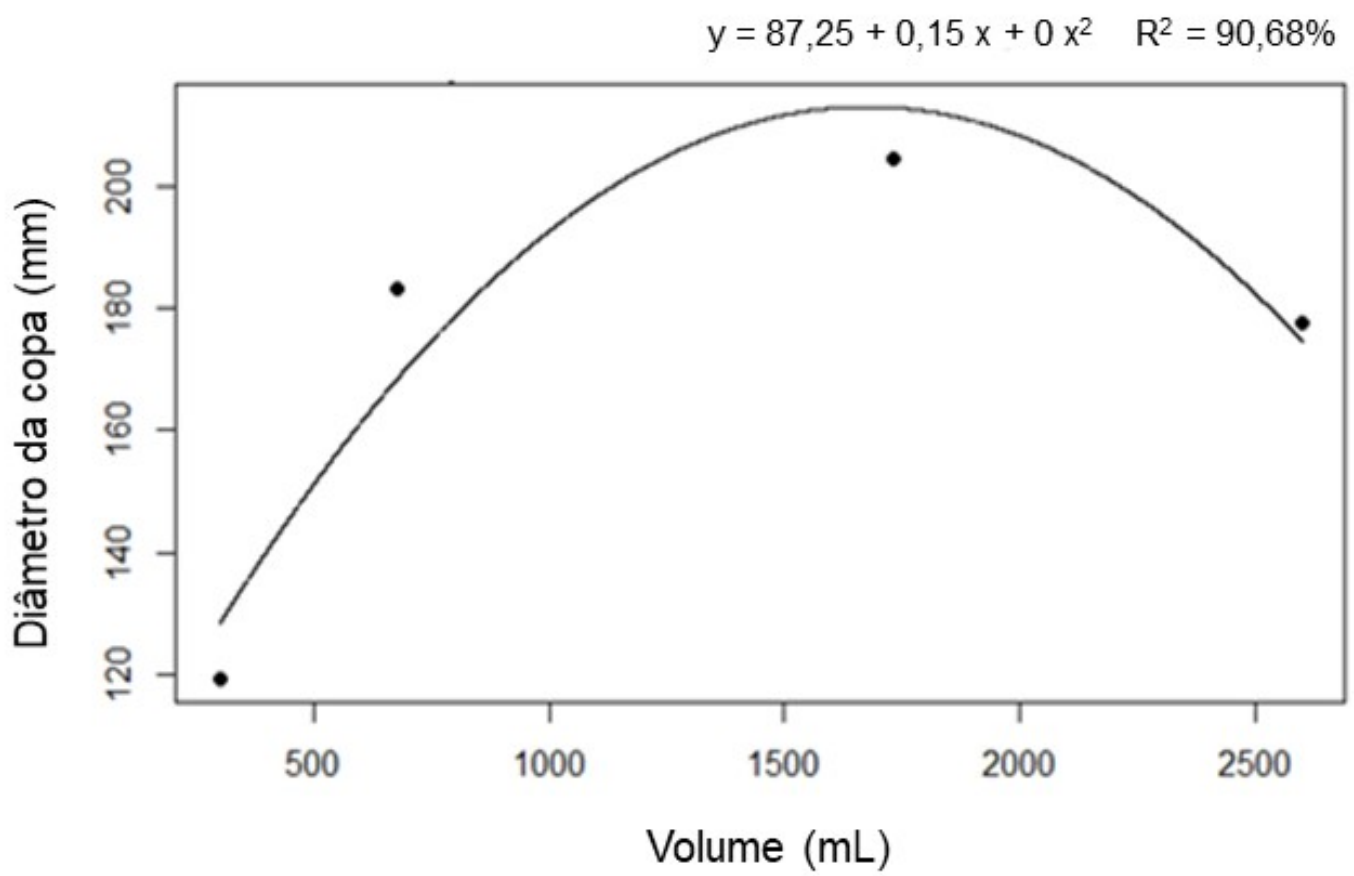

Figura 3. Diâmetro da copa de três genótipos de pimenteiras ornamentais cultivadas em recipientes de diferentes volumes. Floriano-PI, Brasil, 2019.

O diâmetro da copa constitui um elemento importante na determinação da qualidade de uma pimenta ornamental, haja vista que exerce um papel decisivo na harmonia entre planta e vaso (Barroso et al., 2012). Portanto, objetivando a obtenção das menores dimensões para esta característica sem comprometer a altura das pimentas e os menores custos de produção, os genótipos GEN38 e GEN75 deverão ser cultivadas em vasos V2, enquanto GEN 40 deverá ser mantido em vasos V4.

Para a variável comprimento da folha, houve diferenças significativas entre os genótipos (Tabela 5), sendo o GEN75 aquele com os menores valores médios para a referida característica. 0 comprimento da folha foi influenciado, ainda, pelo volume dos vasos, sendo o modelo quadrático o mais ajustável para esta variável (Figura 4). Os maiores valores para esta característica foram obtidos quando as pimenteiras foram cultivadas em vasos V2.

Tabela 5. Valores médios para comprimento da folha (em $\mathrm{mm}$ ) de três genótipos de pimenteiras com potencial ornamental. Floriano-PI, Brasil, 2019.

\begin{tabular}{|c|c|}
\hline Genótipo & Comprimento da folha \\
\hline GEN38 & $46,7 \mathrm{a}$ \\
\hline GEN40 & $41,7 \mathrm{~b}$ \\
\hline GEN75 & $30,5 \mathrm{c}$ \\
\hline
\end{tabular}

Médias seguidas de mesma letra na coluna não diferem estatisticamente entre si pelo teste de Tukey a $5 \%$ de probabilidade. 


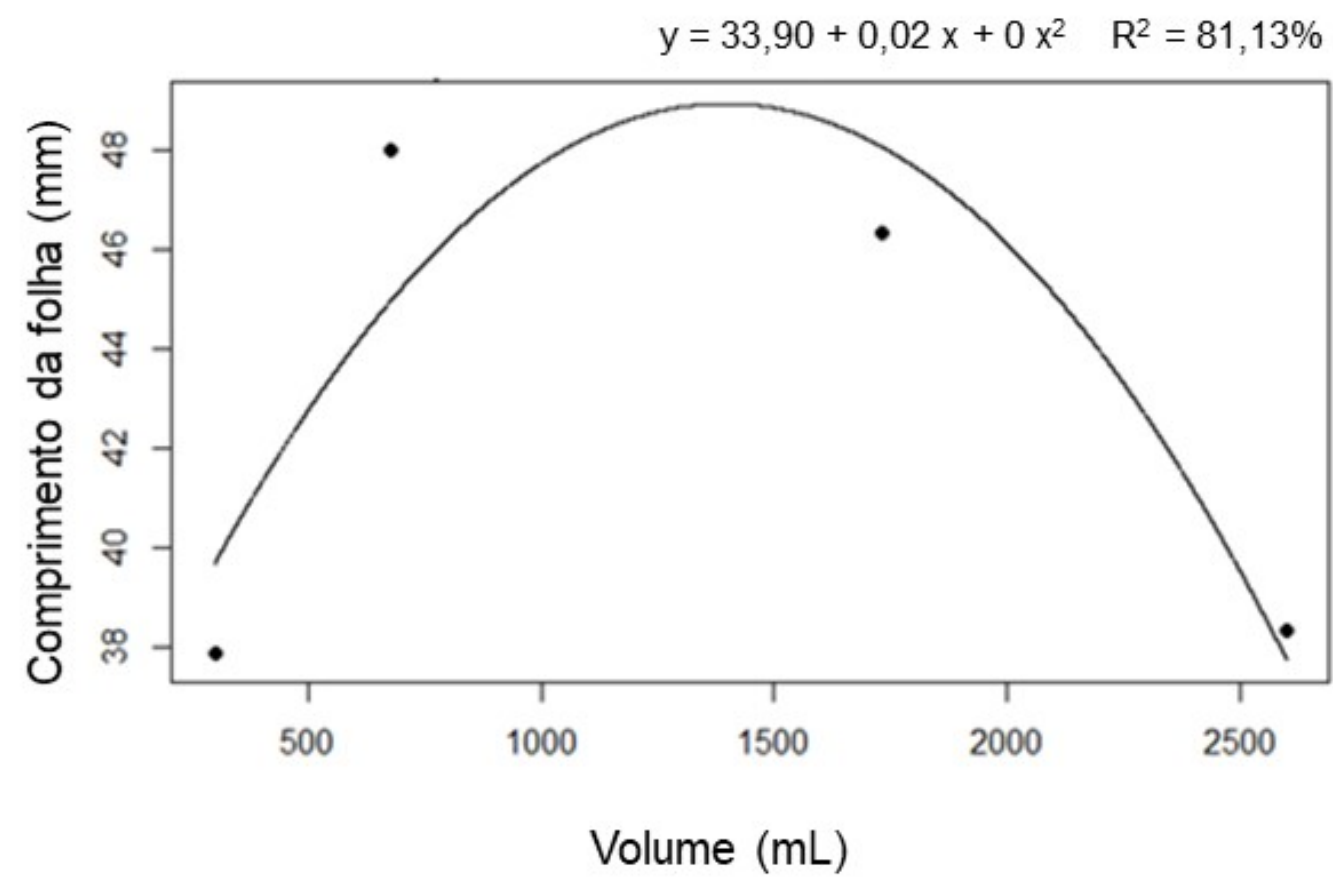

Figura 4. Comprimento da folha de três genótipos de pimenteiras ornamentais cultivadas em recipientes de diferentes volumes. Floriano-PI, Brasil, 2019.

A interação genótipo x volume foi capaz de alterar significativamente a largura da folha (Tabela 6). Para o GEN38 (Figura 5A) e GEN75 (Figura 5C) o modelo de regressão que melhor que se ajustou foi o quadrático, sendo os vasos V3 e V4 capazes de fornecerem, respectivamente, os maiores valores médios para largura da folha nestes genótipos. Já para o GEN40, observou-se um comportamento linear entre largura da folha e o volume dos recipientes (Figura 5B).

Tabela 6. Valores médios para largura das folhas de pimenteiras com potencial ornamental cultivadas em recipientes de diferentes volumes. Floriano-PI, Brasil, 2019.

\begin{tabular}{|c|c|c|c|c|}
\hline \multirow{2}{*}{ Genótipo } & \multicolumn{4}{|c|}{ Volume } \\
\cline { 2 - 5 } & $\mathbf{3 0 0} \mathbf{~ m L}$ & $\mathbf{6 8 0} \mathbf{~} \mathbf{L}$ & $\mathbf{1 . 7 3 0} \mathbf{~ m L}$ & $\mathbf{2 . 6 0 0} \mathbf{~ m L}$ \\
\hline GEN38 & $16,3 \mathrm{a}$ & $18,4^{\mathrm{a}}$ & $21,6 \mathrm{a}$ & $18,9 \mathrm{~b}$ \\
\hline GEN40 & $16,4 \mathrm{a}$ & $18,6^{\mathrm{a}}$ & $19,8 \mathrm{a}$ & $21,3^{\mathrm{a}}$ \\
\hline GEN75 & $13,4 \mathrm{~b}$ & $14,7 \mathrm{~b}$ & $15,3 \mathrm{~b}$ & $15,6 \mathrm{c}$ \\
\hline
\end{tabular}

Médias seguidas de mesma letra na coluna não diferem estatisticamente entre si pelo teste de Tukey a $5 \%$ de probabilidade. 

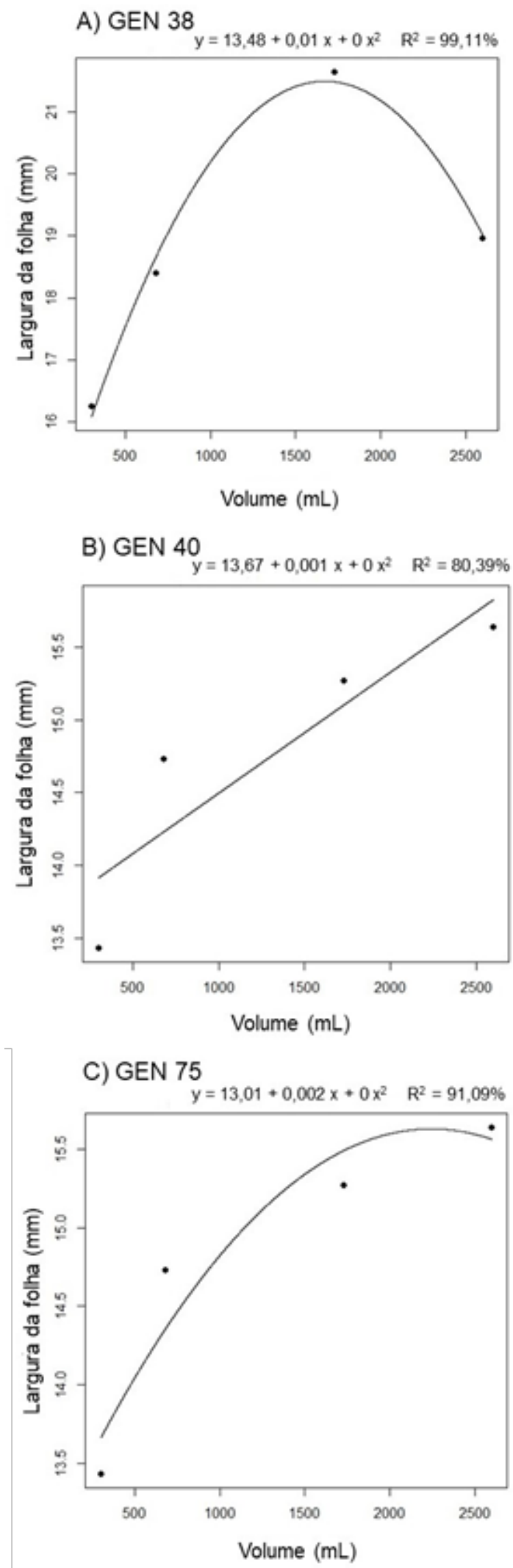

Figura 5. Largura da folha de três genótipos de pimenteiras ornamentais cultivadas em recipientes de diferentes volumes. Floriano-PI, Brasil, 2019. 
O comprimento e largura das folhas constituem características de extrema relevância, haja vista a direta relação entre a área foliar, fotossíntese e o crescimento e desenvolvimento das plantas (Taiz e Zeiger, 2013). Barroso et al. (2012) afirmam, porém, que para fins ornamentais, interessam, sobretudo, genótipos de pimenteiras contendo folhas com menores dimensões. Portanto, apesar de garantirem os maiores valores para comprimento da folha, sugere-se que GEN38 e GEN40 sejam cultivados em vaso V2, capaz de assegurar uma menor largura das estruturas foliares. Já o GEN75 deverá ser cultivado em vasos V4 uma vez que, apesar de este fornecer os maiores valores para largura da folha, permitiu a obtenção das menores médias para o seu comprimento, sem comprometer as demais características avaliadas (altura e diâmetro da copa).

\section{Conclusões} ornamental.

Os indivíduos GEN38, GEN40 e GEN75 constituem genótipos com potencial

$\mathrm{O}$ vaso $\mathrm{V} 1$ (300 $\mathrm{mL}$ ) apresenta-se como impróprio para o cultivo de pimenteiras.

Recomenda-se o cultivo dos genótipos GEN38 e GEN75 em vaso V2 (680 mL).

O GEN40 deve ser produzido utilizando-se o recipiente V4 (2.600 mL).

Dentre os substratos utilizados, recomenda-se o de menor custo: S3, composto por esterco caprino, esterco bovino, palha de arroz e areia.

\section{Agradecimentos}

À Universidade Federal do Piauí, Campus Amílcar Ferreira Sobral (UFPI-CAFS) e ao Colégio Técnico de Floriano (CTF) pela concessão de recursos materiais e humanos empregados nesta pesquisa.

\section{Conflito de interesses}

Os autores declaram não haver conflito de interesses.

\section{Referências}

Almeida, M. O.; Matos, C. D. C. D.; Silva, D. V.; Braga, R. R.; Ferreira, E. A.; Santos, J. B. D. Interação entre volume de vaso e competição com plantas daninhas sobre o crescimento da soja. Revista Ceres, v. 62, n. 6, p. 524-530, 2015. https://doi.org/10.1590/0034737X201562060003

Araújo Neto, S. E. D.; Azevedo, J. M. A. D.; Galvão, R. D. O.; Oliveira, E. B. D. L.; Ferreira, R. L. F. Produção de muda orgânica de pimentão com diferentes substratos. Ciência Rural, v. 39, n. 5, p. 1408-1413, 2009. https://doi.org/10.1590/S0103-84782009005000099.

Barroso, P. A.; Rêgo, E. R.; Rêgo, M. M.; Nascimento, K. S.; Nascimento, N. F. F.; Nascimento, M. F.; Soares, W. S.; Ferreira, K. T. C.; Otoni, W. C. Analysis of segregating generation for components of seedling and plant height of pepper (Capsicum annuum L.) for medicinal and ornamental purposes. Acta Horticulturae, v. 953, p. 269-275, 2012. http://doi.org/10.17660/ActaHortic.2012.953.37

Büttow, M. V.; Barbieri, R. L.; Neitzke, R. S.; Heiden, G.; Carvalho, F. I. F. D. Diversidade genética entre acessos de pimentas e pimentões da Embrapa Clima Temperado. Ciência

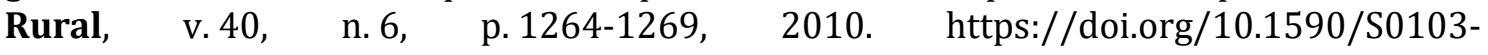
84782010000600004 
Carpentieri-Pípolo, V.; Destro, D.; Prete, C. E. C.; Gonzales, M. G. N.; Popper, I.; Zanatta, S.; Silva, A. Seleção de genótipos parentais de acerola com base na divergência genética multivariada. Pesquisa Agropecuária Brasileira, v. 35, n. 8, p. 1613-1619, 2000. https://doi.org/10.1590/S0100-204X2000000800014

Carvalho, S. I. C.; Bianchetti, L. D. B.; Ribeiro, C. D. C.; Lopes, C. A. Pimentas do gênero Capsicum no Brasil. Brasília: Embrapa Hortaliças, 2006.

Filgueira, F. A. R. Novo manual de olericultura: agrotecnologia moderna na produção e comercialização de hortaliças. Viçosa: UFV, 2008. v. 3.

Furtini Neto, A. E.; Boldrin, K. V. F.; Mattson, N. S. Nutrition and quality in ornamental plants. Revista Brasileira de Horticultura Ornamental, v. 21, n. 2, p. 139-150, 2015. https://doi.org/10.14295/aohl.v21i2.809

Junqueira, A. H.; Peetz, M. S. O setor de flores e plantas ornamentais no Brasil no período de 2008 a 2013: atualizações, balanços e perspectivas. Revista Brasileira de $\begin{array}{lllll}\text { Horticultura } & \text { Ornamental, } & \text { v. 20, } & \text { n. 2, } & \text { p. 115-120, }\end{array}$ https://doi.org/10.14295/rbho.v20i2.727

Lima, I. B.; Santos, A. B.; Fonseca, J. J. S.; Takane, R. J.; Lacerda, C. F. Pimenteira ornamental submetida a tratamentos com daminozide em vasos com fibra de côco ou areia. Semina: Ciências Agrárias, $\quad$ v. 1, $\quad$ n. 34, $\quad$ p. 3597-3610, $2013 . \quad$ http://10.5433/16790359.2013v34n6Supl1p3597

Melo, L. F.; Gomes, R. L. F.; Silva, V. B. D.; Monteiro, E. R.; Lopes, A. C. A.; Peron, A. P. Potencial ornamental de acessos de pimentas. Ciência Rural, v. 44, n. 11, p. 2010-2015, 2014. https://doi.org/10.1590/0103-8478cr20131306

Neitzke, R. S.; Barbieri, R. L.; Rodrigues, W. F.; Corrêa, I. V.; Carvalho, F. I. Dissimilaridade genética entre acessos de pimenta com potencial ornamental. Horticultura Brasileira, v. 28, n. 1, p. 47-53, 2010. https://doi.org/10.1590/S0102-05362010000100009

Neitzke, R. S.; Fischer, S. Z.; Vasconcelos, C. S.; Barbieri, R. L.; Treptow, R. O. Pimentas ornamentais: aceitação e preferências do mercado consumidor. Horticultura Brasileira, v. 34, n. 1, p. 102-109, 2016. https://doi.org/10.1590/S0102-053620160000100015

Neves, M. F.; Pinto, M. J. A. Mapeamento e quantificação da cadeia de flores e plantas ornamentais do Brasil. São Paulo: OCESP, 2015.

Pinto, C. M. F.; Barbosa, J. M.; Mesquita, D. Z.; De Oliveira, F.; Mapeli, A. M.; Segatto, F. B.; Barbosa, J. G. Produção e qualidade de pimentas ornamentais comestíveis cultivadas em recipientes de diferentes volumes. Revista Brasileira de Horticultura Ornamental, v. 16, n. 1, p. 113-122, 2010. https://doi.org/10.14295/rbho.v16i1.519

Pinto, C. M. F.; Pinto, C. L. O.; Donzeles, S. M. L. Pimenta Capsicum: propriedades químicas, nutricionais, farmacológicas e medicinais e seu potencial para o agronegócio. Revista

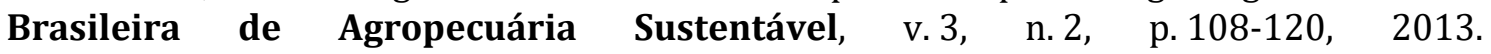
https://doi.org/10.21206/rbas.v3i2.225

R Core Team. R: A linguage environment for statistical computing. R Foundation for Statistical Computing. Vienna: R Core Team, 2019.

Rêgo, E. R.; Nascimento, M. F.; Nascimento, N. F. F.; Santos, R. M. C.; Fortunato, F. L. G.; Rego, M. M. Testing methods for producing self-pollinated fruits in ornamental peppers. Horticultura Brasileira, v. 30, n. 4, p. 669-672, 2012. http://doi.org/10.1590/S010205362012000400017 
Santos Pessoa, A. M.; Rêgo, E. R.; Santos, C. A. P.; Rêgo, M. M. Genetic diversity among accessions of Capsicum annuum L. through morphoagronomic characters. Genetics and Molecular Reseach, v. 17, n. 1, p. 2-15, 2018. http://doi.org/10.4238/gmr16039883

Silva, C. Q.; Jasmim, J. M.; Santos, J. O.; Santos Bento, C.; Sudré, C. P.; Rodrigues, R. Phenotyping and selecting parents for ornamental purposes in pepper accessions. Horticultura Brasileira, v. 33, n. 1, p. 66-73, 2015. https://doi.org/10.1590/S0102053620150000100011

Silva, C. Q.; Rodrigues, R.; Bento, C. S.; Pimenta, S. Heterosis and combining ability for ornamental chili pepper. Horticultura Brasileira, v. 35, n. 3, p. 349-357, 2017. http://doi.org/10.1590/s0102-053620170306

Taiz, L.; Zeiger, E. Fisiologia vegetal. 5. ed. Porto Alegre: Artmed, 2013.

Veiling Holambra. Pimenta ornamental de vaso. 2019. Disponível em <http://veiling.com.br/uploads/padrao/pimenta-ornamental-po.pdf>. Acesso em: $02 \mathrm{dez}$. 2019.

Informação da Licença: Este é um artigo Open Access distribuído sob os termos da Licença Creative Commons Attribution, que permite uso irrestrito, distribuição e reprodução em qualquer meio, desde que a obra original seja devidamente citada. 